
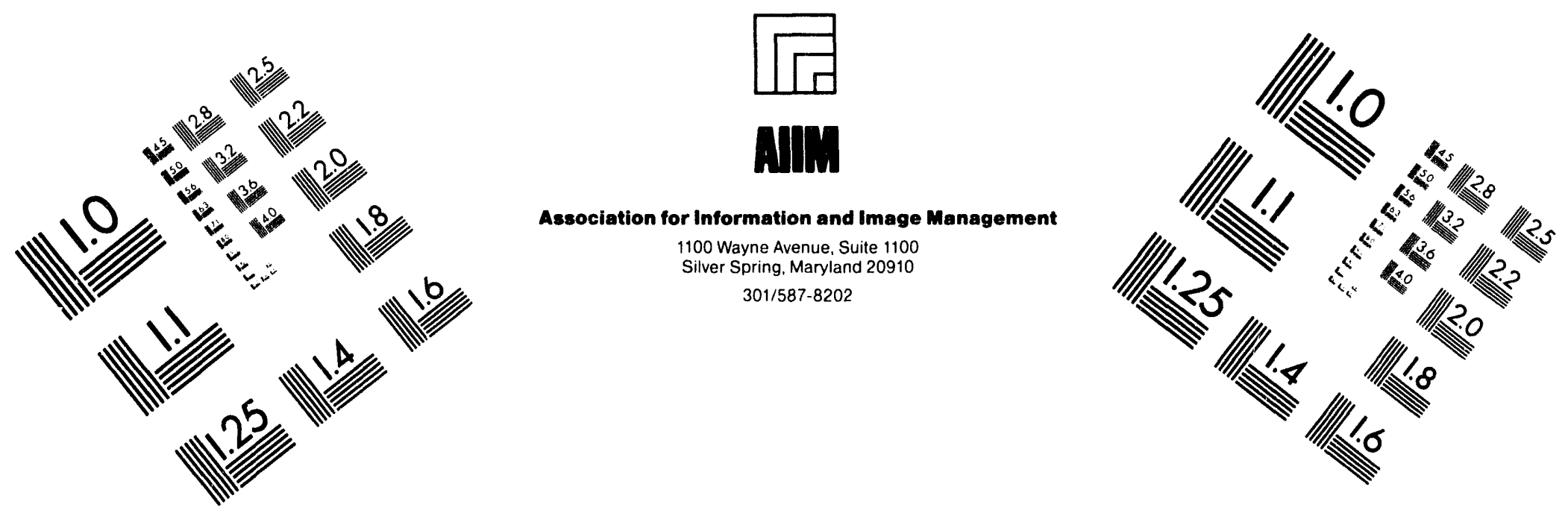

\title{
Centimeter
}

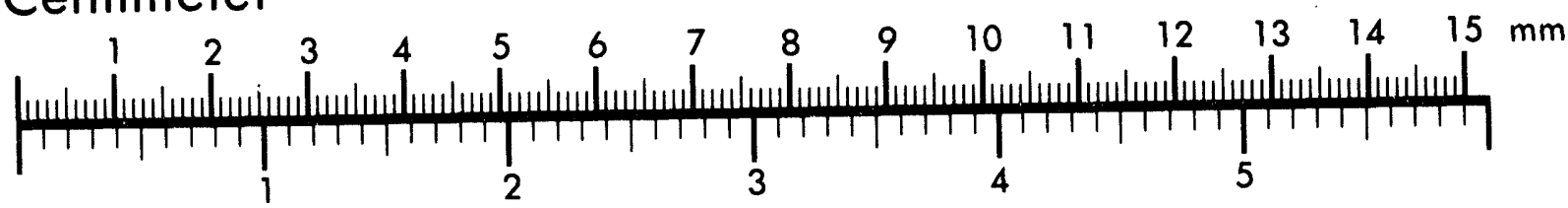
Inches
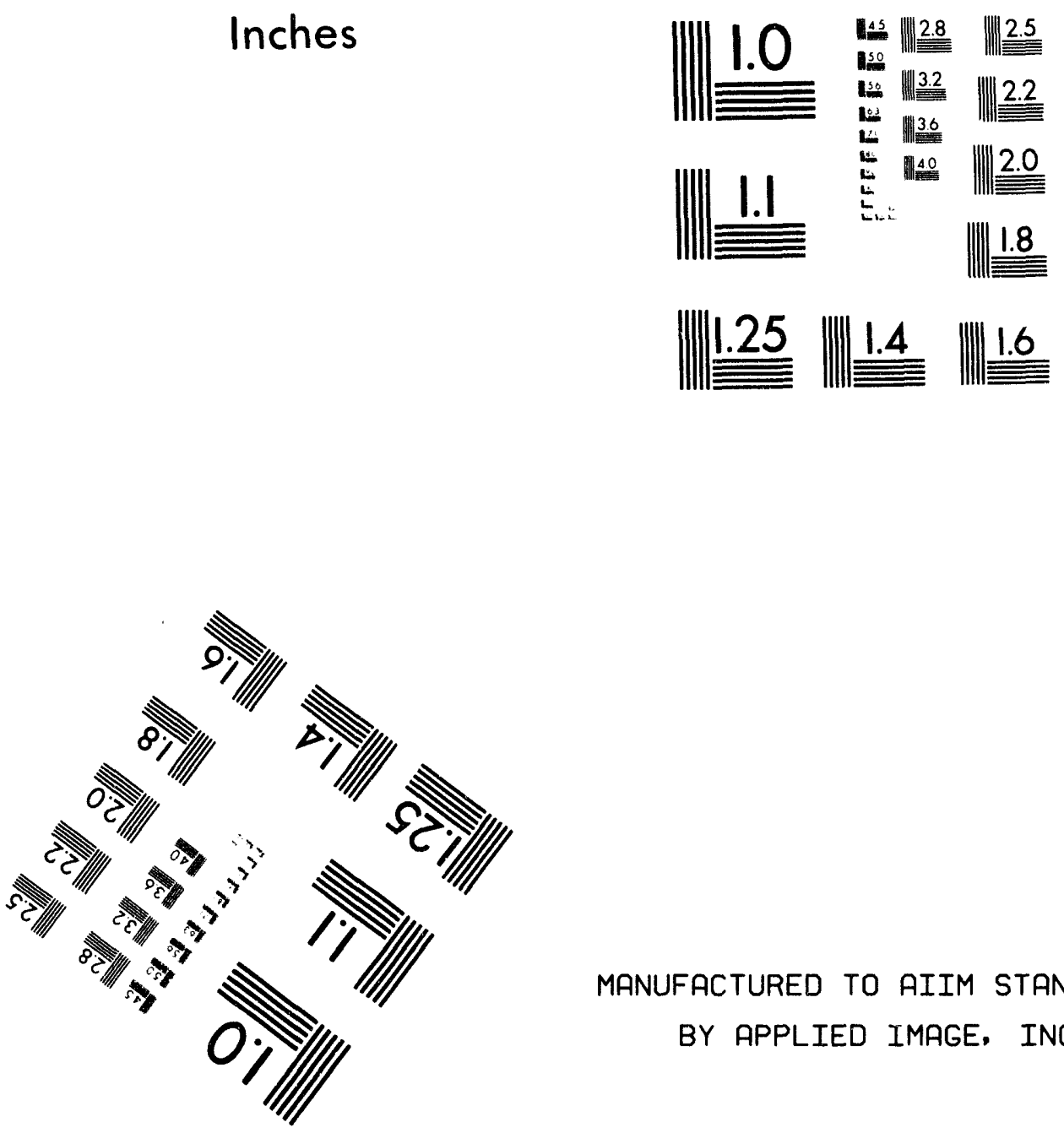

MANUFACTURED TO AIIM STANDARDS BY APPLIED IMAGE, INC.

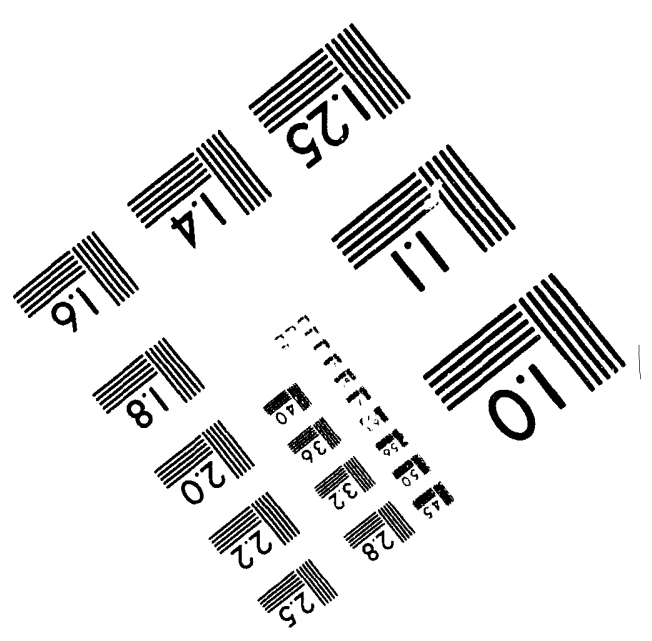



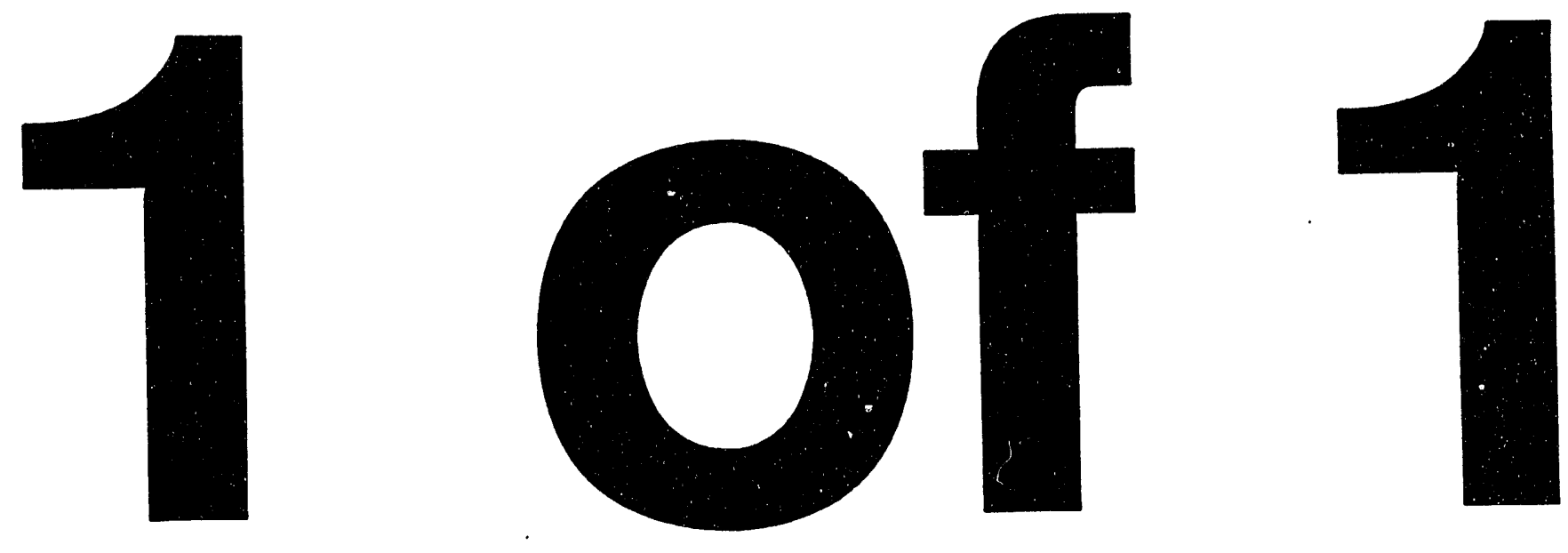


\section{ION EXCHANGE AND ADSORPTION ON LOW RANK COALS FOR LIQUEFACTION}

by Karl s. Vorres

Conf-9409/68--3

Chemistry Division, Building 211

Argonne National Laboratory

Argonne, IL 60439

\section{OBJECTIVES :}

The objectives of this program are to study the application of catalysts and the catalysis of liquefaction of low rank coals. Ion exchange and adsorption techniques are being used or modified to incorporate catalytically active metals ( $\mathrm{Fe}, \mathrm{Co}, \mathrm{Ni}$ and $\mathrm{Mo}$ ) in relatively small (100-2000 ppm) quantities into coal samples. Relative oil yields are being determined by PETC and Auburn University workers as collaborators to establish the effectiveness of the catalyst incorporation techniques. It is hoped that these techniques will provide highly active forms of the catalyst in low concentrations to minimize the need for metals recovery.

\section{INTRODUCTION:}

Ion exchange, adsorption and small particle techniques have been used by a number of workers to facilitate the conversion of coal to transportation and other fuels from coal (1-7). This is one of the programs. A study of the ion exchange process and related phenomena have been carried to optimize this step for a range of coals. Coal conversion studies have shown that the conversion is sensitive to the pretreatment and catalyst loading.

The focus of this program is to investigate one approach to develop a more economical means of converting the low rank coals to synthetic transportation fuels. This approach uses ion exchange techniques to place small amounts of highly active catalysts on the coal to explore the range of capabilities of this technique. A two step preparation of the coal is used to (1) remove material which both limits oil conversion and prepares for the addition of exchangeable catalyst, and (2) add catalytically active material which enhances the conversion of the coal matter to the oil fraction in the processing.

\section{EXPERIMENTAL:}

Coal Samples

The coal samples include those from the Argonne premium coal Sample Program (8), chosen because they represent a near pristine material, are well characterized, available in uniform lots and the same as or very similar to coals used by other investigators. A Black Thunder coal was also obtained from the Amoco Company after treatment with sulfurous acid. The samples for liquefaction evaluation included the prepared material, before and afte: acid treatment, and the samples with catalyst added.

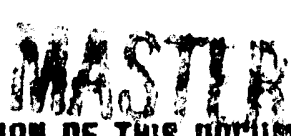

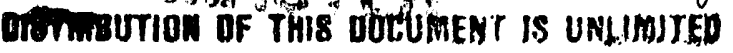

The submitted manuscript has been authored by a contractor of the U.S. Government by a contractor of the U. S. Government Accordingly, the U.S. Government retains a nonexclusive, royalty.free license to publish or reproduce the published form of this contribution, or allow others to do so, for U. S. Government purposes. 


\section{DISCLAIMER}

This report was prepared as an account of work sponsored by an agency of the United States Government. Neither the United States Government nor any agency thereof, nor any of their employees, makes any warranty, express or implied, or assumes any legal liability or responsibility for the accuracy, completeness, or usefulness of any information, apparatus, product, or process disclosed, or represents that its use would not infringe privately owned rights. Reference herein to any specific commercial product, process, or service by trade name, trademark, manufacturer, or otherwise does not necessarily constitute or imply its endorsement, recommendation, or favoring by the United States Government or any agency thereof. The views and opinions of authors expressed herein do not necessarily state or reflect those of the United States Government or any agency thereof. 
The Argonne coal samples used for elution/ion exchange to date were the wyodak subbituminous (WY), Illinois \#6 (IL) high volatile bituminous, Beulah-Zap lignite (ND), Blind Canyon (UT) and Lewiston-stockton (WV) high volatile bituminous (19). A typical run would begin with 30 or 40 grams of the -20 mesh samples which were dry screened to $-20+200$ mesh.

\section{Slurry pH}

Since the inorganic and carboxylate components may affect the ion exchange results, a series of slurry $\mathrm{pH}$ measurements was made on the 8 Argonne Premium Coal samples to provide a basis for comparison, and examine trends.

Slurry pH measurements were made using a technique similar to that described by Brockway and Higgins (9). For each of the eight coals, five gram ampoules of -100 mesh coal were mixed with water using twice the weight of coal, stirred well and allowed to stand for 30 minutes before taking the $\mathrm{pH}$ with a $\mathrm{pH}$ electrode immersed in the slurry.

\section{Elution of Cations from Coals}

Weighed amounts (about 30 grams) of the screened samples were slurried with distilled or deionized water. Fines (still -200 mesh) were decanted away from the slurry using about 200-600 ml of water. The slurry was washed into a special $50 \mathrm{ml}$ burette. The burette had been fitted with a coarse fritted glass disk at the $50 \mathrm{ml}$ mark to retain the coal but allow solutions to pass. Fine coal particles ( -200 mesh) had to be removed to avoid pluggage of the frit. A peristaltic pump or later a siphon provided a uniform flow of standardized $0.100 \mathrm{~N} \mathrm{HNO}_{3}$ or distilled water to the sample. Acid or water flow rates were typically about $1-3$ $\mathrm{ml} / \mathrm{minute}$ and were set according to the ability of the solution to pass through the coal bed. Following the treatment with the acid, the samples were washed with distilled water, and the record of $\mathrm{pH}$ and ion concentration was again obtained.

The burette tip was fitted with tubing to connect flow-through $\mathrm{pH}$ and ion-selective ( $\mathrm{Ca}^{+2}, \mathrm{Na}^{+}$and $\mathrm{K}^{+}$) electrodes from Cole-Parmer, or from Microelectrodes, Inc (Londonderry, $\mathrm{NH}$ ). The electrodes were used with an orion EA940 pH meter and model 607 switchbox. The pH meter in turn was connected to an IBM model AT computer for data acquisition. A schematic diagram of the equipment is given in Figure 1. A program was written which allowed data points to be acquired at specific intervals in the range of 10-18 seconds. The data files were then manipulated with Lotus 123 macros to permit plots to be drawn of the data. Workers contemplating building a similar system should be aware that the documentation of the interfacing is exceedingly brief and the quality of technical service for the instrumentation may cause considerable delays in setting up such a system.

The pH electrodes were calibrated with cole Parmer standard buffers of $\mathrm{pH} 4.00$ and 7.00. The ion selective electrodes were calibrated with standard solutions made up of a series of 
analyzed reagents salts diluted to give $0.10,0.010$ and $0.0010 \mathrm{M}$ solutions for each of the cations. Calibrations were checked at the end of the runs. The response of the ion selective electrodes is dependent on the ionic strength of the solutions, which changes during the course of an experiment. The values given here are good for comparison purposes, but are not intended to serve as reference analytical numbers.

Treatment with Catalytically Active Metals

Initial experiments indicated that ion exchange was slow. The weight of standard catalyst solutions required to give $2000 \mathrm{ppm}$ of catalyst if all of the cations were exchanged was calculated. This amount was added to the coal slurry, stirred well and allowed to exchange for about 42 hours. The solutions were then decanted into tared bottles, and the slurry rinsed three times into the tared bottles with distilled water. The weight of the solution was determined and a sample submitted for analysis. From the difference of the total amount of metal available, and the amount in the solution, and the weight of the coal, the loading of the coal was calculated.

Determination of Conversion to Liquid Products

Samples have been evaluated by groups at PETC (Anthony Cugini) and Auburn University (C. J. Brannan and Christine W. Curtis).

Samples were run in microautoclave tubing bombs to establish liquefaction yields based on THF solubility (total conversion) and in some cases heptane soluble (oil yield). Conditions were: solvent 1-MeNapthalene (non-donor), $2: 1$ solvent:coal; $425^{\circ} \mathrm{C}, 30$ minute reaction, cold charge at 1000 psi H2, (1700-1800 hot). In some cases, as noted, elemental sulfur was added to sulfide the catalysts.

RESULTS AND DISCUSSION:

$\mathrm{pH}$ of slurries

The results obtained from the method of Brockway and Higgins (16) are listed below:

Coal

Upper Freeport

$\mathrm{pH}$

Wyodak

8.59

7.59

Illinois \#6

8.51

Pittsburgh

9.23

Coal

Pocahontas

$\mathrm{pH}$

There are at least two noteworthy observations about these measurements. First, all of the pH values are above 7.00, indicating that some species are causing the system to be alkaline. Second, there are no known organic species in these samples that would cause the system as a whole to be alkaline, implying that there must be an inorganic cause. 
The $\mathrm{pH}$ values do not correlate with rank or carbon content of the coal or with total ash or total mineral matter content.

The analysis of the mineral matter in the original coal is indicated below: (Data from Illinois state Geological survey, Richard Harvey, November 15,1988

Results of Mineral Analyses, (dry coal basis)

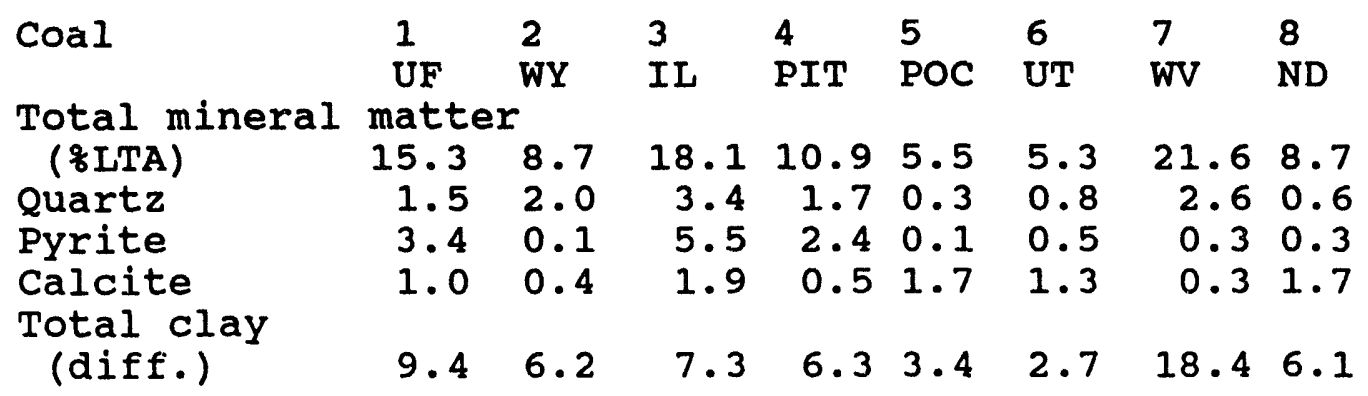

The Total ITA refers to total mineral matter (dry basis) determined as low temperature ash using an oxygen plasma. The total clay (determined by difference) includes illite, kaolinite and expandable clays in unspecified amounts. The best fit for a regression analysis for mineral matter constituents gave an $R$ squared value of only .758. This is possibly due to the fact that the clays do not all behave in the same way. The $R$ squared value was almost as good $(.748)$ without the clays.

The sequence of $\mathrm{pH}$ from Pittsburgh to Wyodak approximates the order of the acidity of the mineral matter in the coal. The most acidic ashes or mineral matter have the highest $\mathrm{SiO}_{2}$ content.

The Major and Minor Elements in the Ash ( $\%$ ) are listed below:

\begin{tabular}{|c|c|c|c|c|c|c|c|c|}
\hline $\begin{array}{l}\mathrm{Al}_{2} \mathrm{O}_{3} \\
\mathrm{BaO}\end{array}$ & $\begin{array}{l}U F \\
24.1 \\
0.05\end{array}$ & $\begin{array}{l}\text { WY } \\
15.5 \\
0.5\end{array}$ & $\begin{array}{l}\text { IL } \\
18.3\end{array}$ & $\begin{array}{l}\text { PITT } \\
25.2\end{array}$ & $\begin{array}{r}\text { POC } \\
20.1\end{array}$ & $\begin{array}{l}\text { UT } \\
16.6\end{array}$ & $\begin{array}{l}\text { WV } \\
31.35 \\
.02\end{array}$ & $\begin{array}{c}\text { ND } \\
10.22 \\
.84\end{array}$ \\
\hline $\mathrm{CaO}$ & 4.2 & 15.1 & 7.9 & 2.6 & 12.8 & 9.9 & .38 & 24.72 \\
\hline $\mathrm{Fe}$ & 17.3 & 10.2 & 18.0 & 19.5 & 15.8 & 10.0 & 2.89 & 8.00 \\
\hline & 2.7 & 0.8 & 2.9 & 2.1 & 0.6 & 1.2 & 2.92 & .94 \\
\hline Mğo & 1.6 & 3.6 & 1.2 & 1.3 & 2.0 & 1.5 & 0.73 & 7.48 \\
\hline $\mathrm{Mn}$ & 0.05 & 0.04 & & & & & 0.04 * & 0.14 * \\
\hline $\mathrm{Na}$. & 0.0 & 1.5 & 0.0 & 0.0 & 2.0 & 3.6 & 0.34 & 7.76 \\
\hline & 0.1 & 1.2 & 0.2 & 0.0 & 0.4 & 0.3 & 0.20 & 0.48 \\
\hline & 3.9 & 22.0 & 6.8 & 2.0 & 12.4 & 9.8 & 0.32 & 17.55 \\
\hline Sic & 44.8 & 28.7 & 43.7 & 45.9 & 32.0 & 45.9 & 58.26 & 18.40 \\
\hline Sr & 0.05 & 0.4 & & & & & 0.05 & 1.12 \\
\hline $\mathrm{TiO}_{2}$ & 1.3 & 1.2 & 1.0 & 1.2 & 1.9 & 1.2 & 1.86 & 0.48 \\
\hline & ned & & & & & & 0.64 & 1.87 \\
\hline
\end{tabular}

A regression analysis was done to establish a relationship between the measured $\mathrm{pH}$ and the reported values for the oxides. The regression analysis generated the equation using Lotus 123: 
$\mathrm{pH}=0.57+.093 * \mathrm{SiO}_{2}+.159 * \mathrm{Al}_{2} \mathrm{O}_{3}+.225 * \mathrm{FeO}_{\mathrm{x}}+.166 * \mathrm{CaO}$ $-0.45 * \mathrm{~K}_{2} \mathrm{O}-1.26 * \mathrm{TiO}_{2}$.

The $R$ squared value was .999, with the standard error of pH at .039. This equation makes the pH extremely dependent on values for $\mathrm{K}$ and $\mathrm{Ti}$. Additional data for other coals would be helpful to confirm this relationship. The change of signs from + to for $\mathrm{Ti}$, and the + sign for CaO were not expected.

Yun and coworkers (10) noted a change in pH titration curves with oxidation. It is proposed that the regression line gives values for pristine samples and that studies of carefully oxidized coals may permit a method to quickly indicate the amount of oxidation of a given sample from a knowledge of the slurry $p H$ and the elemental composition of the coal ash.

\section{Elution of Cations from Coals with Acid Solutions}

Acid Treatment Requirements

The acid treatment of the coal samples serves two purposes: calcium removal and exchange site formation. Both goals may be achieved with the acid removal of calcium bound to carboxylate sites. However significant amounts of calcium may be present in other forms, sucil as the mineral calcite.

In order to determine how many sites are being made available, and whether these will be sufficient for the desired catalyst loading, titration curves were obtained. These curves plot the $\mathrm{pH}$ as known amounts of acid are added to the coal sample. A typical curve involves a plateau or gently descending slope as the acid removes exchangeable cations from the coal and replaces them with hydrogen ions. These hydrogen ions can later be replaced by the catalytic metals ( $\mathrm{Fe}$ or $\mathrm{Co}$ or $\mathrm{Ni}$ ) in the ion exchange step.

The lower rank coals contain a substantial amount of alkali and alkaline earth cations attached to carboxylate groups. Not all of these alkalies in the coal are attached to organic groups. Some alkalies are contained in the mineral matter, such as clays. Data were also obtained with ion selective electrodes. The titration curves were then obtained for not only $\mathrm{pH}$ but the $\mathrm{Ca}$, $\mathrm{Na}$ and $K$ concentrations at the same time. The amount of exchangeable calcium or other cations can be approximated from the titration curves. The runs with wyodak did not involve all electrodes at first.

The atomic weight of calcium is 40 and the atomic weights of $\mathrm{Fe}$, $\mathrm{Co}$ and $\mathrm{Ni}$ are 56, 59 and 59. In order to place $1000 \mathrm{ppm}$ by weight of catalytic metal on the samples it is necessary to remove about 0.7 milligrams of exchangeable calcium or equivalent per gram of coal. This would require reaction with about $.175 \mathrm{ml}$ of $0.100 \mathrm{~N} \mathrm{HNO}_{3}$ for singly bonded $\mathrm{Ca}$ or abuut . $35 \mathrm{ml}$ for doubly bonded $\mathrm{Ca}$ per gram of coal. This amount has been exceeded in the lower rank coals.

Acid Treatment of Wyodak Samples 
The results for a Wyodak sample with the $\mathrm{pH}, \mathrm{Ca}$ and $\mathrm{Na}$ electrode are shown in Figure 2. The $\mathrm{pH}$ changes for the wyodak coal titrated with $0.100 \mathrm{~N}$ nitric acid indicate an initial period in which the water in contact with the coal was displaced by the acid ( $\mathrm{pH}$ about 8 to 5.5). During this time no significant amount of inorganic cations were evolved. This period was followed by an extensive period in which the $\mathrm{pH}$ was almost constant at about 6. During this time the other cations associated with carboxylate groups were exchanging with hydrogen ions and being eluted. The calcium was evolved in different stages, reflecting the possibility of bonding at one or two sites, and also the dissolution of some calcite in the coal. The scatter in values for the calcium values at higher concentrations is attributed to the release of carbon dioxide bubbles which affects the flow-through electrode stability. At the end of this phase a pair of inflections was exhibited before reaching the $\mathrm{pH}$ of the input arid. The Na electrode indicated that the $\mathrm{Na}$ was eluted early in the exchange process, and in this representation tailed off slowly. The Na values are not reliable below $\mathrm{pH} 4$ due to interference from hydrogen ions.

Water Rinse of Wyodak Samples

Figure 3 shows the effects of rinsing the acid washed coal with distilled water. It should be noted that the coal changes character in the process and the rate of passage of the deionized water decreased.

One characteristic of the water washing step is the release of some calcium at about $\mathrm{pH}$ 1.5. This is seen in Figure 3 and is reproducible through several stages of acid washing and water rinsing. The shape of the curve is consistent through 3 wash and rinse sequences. In each case the calcium is rinsed out near the same pH. The calcium is also washed out in successive acid washes in a slightly higher $\mathrm{pH}$ range.

The cause of the release of calcium in both the acid wash and water rinse near the same $\mathrm{pH}$ is not yet clear. clays shrink and swell going through $\mathrm{pH}$ regions near this value and may be releasing $\mathrm{Ca}$ during the swelling as the $\mathrm{pH}$ increases. Subsequent acid washes may remove $C a$ which has diffused to the surface from pores.

Preliminary Treatment of Illinois \#6 Samples

The initial acid titration indicated that a gas is released during the acid washing in the burette. The release of the gas bubbles effectively blocked the flow of the acid solution through the burette. In order to obtain similar data and avoid the problems, a change in the procedure used earlier with the Wyodak coal was made. The $\mathrm{pH}$ of the initial slurry was measured for later reference and then 20.0 grams of $0.100 \mathrm{~N}$ nitric acid was added to about 30 grams of coal to consume some of the calcite in 
the sample. It was assumed that the gas was carbon dioxide which was produced from the reaction of the calcite and the nitric acid.

The treatment of the sample with 20.0 grams of $0.100 \mathrm{~N} \mathrm{HNO}_{3}$ indicated a rapid drop in $\mathrm{pH}$, and then an increase. The shape of the curve of $\mathrm{pH}$ as a function of time begins with a linear segment, followed by another steeper segment and ending with an asymptotic approach to a value around 6 in 2 hours.

Acid Treatment of Illinois \#6 Samples

Following the pretreatment of the Illinois \#6 slurry in the magnetically stirred container, the coal slurry was transferred to the burette. Data were obtained for $\mathrm{pH}$ and concentrations of the $\mathrm{Ca}, \mathrm{Na}$ and $\mathrm{K}$ ions. For this run the $\mathrm{pH}$ data were not as consistent as in the earlier runs. Figure 4 shows the change in pH, and $\mathrm{Ca}$. The sodium electrode gives unreliable data for $\mathrm{pH}$ values below 4 because of interference from the hydrogen ions, so this data was not included. The data do show that there is a release of calcium as soon as the water is displaced by the dilute acid in the burette. The sample is $1.9 \%$ calcite, so a significant amount is expected. The possibility that some of the calcite may be present in small particles embedded within the coal particles would hinder access of the acid and cause a delayed release of the calcium. The release of carbon dioxide bubbles at this time caused significant vaxiations in individual $\mathrm{Ca}$ electrode readings, as seen in the scatter of the points. The titration indicates a significant period during which the $\mathrm{pH}$ changes from about 7 to 5 in a nearly linear manner with time. This could indicate the existence of a series of organic acids of varying strength.

Water Rinse of Illinois \#6 Samples

It was observed, however, that the concentration of potassium in the eluent was greater than calcium, indicating that the calcium was more thoroughly washed out, and that the potassium is released more slowly at this stage. At present it is speculated that these observations are associated with the clays present in each coal. Again, catalyst loading of clay bearing samples may produce two kinds of catalytic species - organically bound and clay-supported.

Beulah-Zap Lignite

The procedures for the acid treatment and elution studies were the same as used for the Illinois samples. Nitric acid (12 gms of $0.1 \mathrm{~N}$ ) was added to remove some of the calcite present in the sample, and avoid problems of gas bubble formation in the burette.

The coal slurry was transferred to the burette, and data were obtained as $0.1 \mathrm{~N} \mathrm{HNO}_{3}$ was added. Figure 5 shows the titration curve. The $\mathrm{Na}$ and $\mathrm{K}$ were initially released, and followed by calcium. While the $\mathrm{Na}$ was eluted at a rate which quickly rose to a maximum, the $\mathrm{K}$ was eluted at a rate which quickly rose to an in- 
termediate value while the $\mathrm{Na}$ was eluted, and then the $\mathrm{K}$ was eluted after the $\mathrm{Na}$ elution began to diminish. The pH remained relatively constant at a little more than 6 during the major part of the acid addition. An initially constant amount of calcium was eluted, indicating a quantity of ions which were equally accessible. Then an increasing amount was released to about three times the earlier concentration. At the time of maximal calcium release, the $\mathrm{pH}$ began to decrease to a value of about 4 and then to the input acid $\mathrm{pH}$ of 1 . The calcium ion concentration decreased uniformly as the pH changed from 6 to 4 , and then dropped sharply as the $\mathrm{pH}$ approached 1 .

A water rinse of the acidified coal sample released $\mathrm{K}$ and $\mathrm{Ca}$ as the $\mathrm{pH}$ ranged from about 1.3 to 2.3 . The $\mathrm{K}$ seemed to precede the elution of $\mathrm{Ca}$. Na may also have been released but could not be determined due to interference by $\mathrm{H}^{+}$with the $\mathrm{Na}$ readings. This is believed to be associated with swelling of the clay in the sample and associated release of the exposed Ca. In successive acid washes, the $\mathrm{Ca}$ and $\mathrm{K}$ appear to be eluted in the range of $\mathrm{pH}$ 3 to 2 , with the $\mathrm{K}$ elution starting just before the $\mathrm{Ca}$.

Application of Catalytic Metals

\section{Ion exchange Techniques}

The acid washed and water rinsed coal samples were treated to incorporate catalytically active metals on the coal. The objective is to use the active acid sites to attach $\mathrm{Fe}$ or $\mathrm{Ni}$ or Co ions, and separately to use the technique developed by schroeder (2) to incorporate Mo on the coal. To date, no reference has been found which describes the ion exchange behavior of these coals well enough to permit the incorporation of $\mathrm{Fe}, \mathrm{Ni}$ or $\mathrm{Co}$ with the certainty that the schroeder method permits for Mo.

For the ion exchange technique to be effective the metal ions must be available in a positively charged form. If the $\mathrm{pH}$ is increased from an acidic value, ion pairs are expected to form (such as $\mathrm{Fe}(\mathrm{OH})^{+}$). These ion pairs are not expected to bond as strongly as the doubly charged cations. In very acidic media the hydrogen ions will not be easily displaced from the coal. This means that there is probably a narrow $\mathrm{pH}$ range where the ion exchange can readily take place. Unfortunately there is no ion selective electrode for these catalytic species, which could permit a speedy optimizing of the conditions for the exchange.

The ion exchange technique is also sensitive to $\mathrm{pH}$ because the surface charges of the coal particles depend on the acicity.

The initial experiments involved samples of Wyodak coal that had been acid washed and rinsed with $1000 \mathrm{ppm}$ solutions of either iron or nickel in $2 \%$ nitric acid. The $\mathrm{pH}$ increased from 1 to 3.5 . The eluent water was collected and analyzed for iron or nickel. The analysis indicated that the coal took up about $125 \mathrm{ppm}$ of either metal. This was much less than the desired $1000 \mathrm{ppm}$. 
These initial efforts indicate that the ion exchange process is a slow one, requiring hours for significant exchange, or that the $\mathrm{pH}$ needs adjustment.

The weight of solution required to give $2000 \mathrm{ppm}$ of catalyst if all of the cations were exchang ed was calculated. This amount was added to the coal slurry described above, stirred well and allowed to exchange for about 42 hours. The solutions were then decanted into tared bottles, and the slurry rinsed three times into the tared bottles with distilled water. The weight of the solution was determined and a sample submitted for analysis. From the difference between the total amount of metal available, and the amount in the solution, and allowing for the weight of the coal, the loading of the coal was calculated.

Results of oil Yield studies

Results have been obtained for raw coal, acid washed coal, and catalyst-containing samples. The coals include the wyodak and Black Thunder subbituminous, and Illinois \#6 high volatile bituminous.

Wyodak subbituminous samples

Samples of the raw coal (directly from the ampoules) were compared with water-washed and acid-washed Wyodak samples. Ash values were also obtained. The water-washed and acid washed samples were dried before the ash determination. Analytical results for the different coal samples, moisture levels to which the samples were dried, measured ash contents, ash content on a dry basis, and the reduction in ash compared to the raw coal are summarized below.

Values in $\%$

Coal Sample

Raw

Water washed

Acid washed

$\begin{array}{lllc}\text { moisture } & \text { ash } & \text { dry ash } & \text { reduction } \\ 27.39 & 6.31 & 8.69 & 0 \\ 6.4 & 7.81 & 8.34 & 4.03 \\ 6.96 & 3.46 & 3.72 & 57.19\end{array}$

Samples were run in microautoclave tubing bombs to establish liquefaction yields based on THF solubility (total conversion) and in some cases heptane soluble (oil yield). These results are summarized below.

Liquefaction results for Wyodak samples:

Raw Sample THF soluble Heptane soluble

(total conv.) (oil yield)

Raw $\quad 55.2,56.1 \quad 34$

Water Washed $44 \quad 27$

Acid washed $\quad 37 \quad 24$

Conditions were: solvent 1-MeNapthalene (MeNap.) (non-donor), 2:1 solvent:coal; $425 \mathrm{C}, 30$ minute reaction, cold charge at 1000 psi H2, (1700-1800 hot). 
. The total conversion and oil yields of the three initial samples decreased with the extent of treatment. This effect may be due to the amount of handling, which represents an opportunity for partial oxidation. The samples were kept under a layer of water to avoid oxidation. However, the nitric acid treatment does give an oxidizing environment. Consideration is being given to alternative acidic treatments to reduce the potential oxidation during the cation removal.

\section{Comparison of Acid Washed Samples}

Samples of acid washed Beulah-Zap, Wyodak and Illinois \#6 were compared in several solvents: 1 methyl naphthalene (1 MeNap., a non-donor solvent); V1074 - a process derived solvent from the pilot plant in wilsonville, $A L ;$ and dihydroanthracene (DHA, a donor solvent).

The results for total conversion are indicated below:

Coal

Beulah-Zap

Wyodak

Illinois \#6
1 MeNap.

73.5

71.4

86.4
V1074

74.1

85.9

86.5
DHA

86.7

86.9

86.4

The reaction conditions were: $410^{\circ} \mathrm{C}, 30 \mathrm{~min}$, no catalyst and $1250 \mathrm{psig} \mathrm{H}_{2}$ introduced at ambient temperature.

The Illinois \#6 sample gave consistent relatively high total conversions. This sample had the highest total sulfur content in these coals. For the Wyodak coal the process derived solvent and the hydrogen donor solvent gave very similar total conversions, while the non-hydrogen donor solvent gave lower conversions. For the Beulah-zap coal, the non-donor solvent and process-derived solvent gave very similar conversions which were less than that obtained with the hydrogen donor solvent, dihydroanthracene (DHA). The process derived solvent is able to promote conversion for higher rank coals better than low rank ones. The DHA gave very similar total conversions with each of the coals. The maf organic sulfur \& values for the Illinois \#6, Wyodak and Beulah$\mathrm{Zap}$ are: $2.38,0.47$ and 0.70 . The pyritic sulfur values are: $2.81,0.17$ and 0.14 .

Comparison of Catalyst-Loaded Samples

subsequent catalyst loading produced a series of samples in several batches to give a variety of loadings in the 100-1000 ppm range. These were also run in microautoclave tubing reactors with Me-Napthalene to establish liquefaction yields based on THF solubility (total conversion) and pyrene conversion (catalyst reactivity).

The samples prepared with $\mathrm{Ni}$ and Co were run about one month after preparation, and the others about two months after.

$T$ lesults of duplicate runs are given below: 


\begin{tabular}{|c|c|c|c|c|}
\hline Sample & $\begin{array}{l}\text { lst } \\
\text { Cat. } \\
\text { Loading } \\
\text { ppm } \\
\text { r }\end{array}$ & $\begin{array}{l}\text { 2nd } \\
\text { Cat. } \\
\text { Loading } \\
\text { ppm }\end{array}$ & $\begin{array}{l}\text { Ave. } \\
\text { Coal } \\
\text { Conv. }\end{array}$ & $\begin{array}{l}\text { Ave. } \\
\text { Pyre } \\
\text { Co }\end{array}$ \\
\hline $\begin{array}{l}\text { One catalyst } \\
\mathrm{BT}-1-\mathrm{Mo} \\
\mathrm{BT}-1-\mathrm{Fe} \\
\mathrm{BT}-1-\mathrm{Co} \\
\mathrm{BT}-1-\mathrm{Ni}\end{array}$ & $\begin{array}{l}\text { metal } \\
829 \\
548 \\
212 \\
257\end{array}$ & & $\begin{array}{l}65.5 \\
60.1 \\
63.3 \\
64.0\end{array}$ & $\begin{array}{l}5.3 \\
3.4 \\
2.9 \\
2.6\end{array}$ \\
\hline $\begin{array}{l}\mathrm{BT}-2-\mathrm{MO} \\
\mathrm{BT}-2-\mathrm{Fe} \\
\mathrm{BT}-2-\mathrm{CO} \\
\mathrm{BT}-2-\mathrm{Ni}\end{array}$ & $\begin{array}{l}418 \\
483 \\
83 \\
464\end{array}$ & & $\begin{array}{l}63.3 \\
65.9 \\
65.1 \\
66.0\end{array}$ & $\begin{array}{l}3.1 \\
3.0 \\
2.9 \\
2.9\end{array}$ \\
\hline $\begin{array}{l}\text { Two catalyst } \\
\text { Fe-Mo-1 } \\
\text { Fe-Mo-2 }\end{array}$ & $\begin{array}{l}\text { metals } \\
456 \\
484\end{array}$ & $\begin{array}{r}210 \\
70\end{array}$ & $\begin{array}{l}69.1 \\
66.5\end{array}$ & $\begin{array}{l}5.3 \\
4.8\end{array}$ \\
\hline $\begin{array}{l}\mathrm{Fe}-\mathrm{Ni}-1 \\
\mathrm{Fe}-\mathrm{Ni}-2\end{array}$ & $\begin{array}{l}408 \\
472\end{array}$ & $\begin{array}{l}224 \\
106\end{array}$ & $\begin{array}{l}67.5 \\
66.4\end{array}$ & $\begin{array}{l}3.9 \\
4.0\end{array}$ \\
\hline \multicolumn{5}{|c|}{ Wyodak Samples } \\
\hline $\begin{array}{l}\text { Wyodak, raw } \\
\text { (no washing) }\end{array}$ & none & & 71.4 & 2.0 \\
\hline $\begin{array}{l}\text { Wyodak, } \\
\text { (nitric acid }\end{array}$ & $\begin{array}{c}\text { none } \\
\text { washed) }\end{array}$ & & 41.6 & 3.1 \\
\hline $\begin{array}{l}\text { (Sulfuric ac } \\
\text { WY-Mo } \\
\text { WY-Fe } \\
W Y-C o \\
W Y-N i\end{array}$ & $\begin{array}{l}\text { id washed) } \\
847 \\
552 \\
668 \\
822\end{array}$ & & $\begin{array}{l}74.2 \\
74.7 \\
53.3 \\
75.5\end{array}$ & $\begin{array}{l}4.5 \\
3.3 \\
2.5 \\
3.1\end{array}$ \\
\hline
\end{tabular}

Cobalt was much more difficult to get on the coal than the Fe or $\mathrm{Ni}$. The analyses of metal loadings are good to 10\%. Individual determination values ranged up to $4 \%$ different from the averages.

For the Black Thunder coal, regardless of the metal type, metal loading or batch, the coal conversion was very similar and ranged for individual determinations from a low of 59\% for Fe batch 1 to a high of 70\% for $\mathrm{Ni}$ batch 2. The coal conversions for the combined metals were slightly higher and less variable than the individual metals. Pyrene conversions tended to be higher for the combined metals than for individual ones.

Wyodak coal which had been acid washed with $\mathrm{H}_{2} \mathrm{SO}_{4}$, with the exception of the co treated sample, gave higher coal conversions than the Black Thunder samples. The primary hydrogenation product produced in each reaction was dihydropyrene. The overall conversions do not appear to be as high as reported for a number of 
- other catalyst preparations. The comparison sample of Wyodak which had been acid washed, but with nitric acid, gave substantially lower total conversion. This may reflect the state of oxidation of the coal.

The pyrene conversion, an indicator of hydrogenation activity, was highest for the Mo catalyst preparations.

\section{CONCLUSIONS:}

1. The slurry $\mathrm{pH}$ of a coal sample can be related to the ash composition of the sample. This measurement technique may be used later to indicate the degree of oxidation of a sample.

2. A number of the ion exchange properties of low rank coals can be observed and understood by titrating with the burette system described. Alkali cations are removed early in the acid titration, and alkaline earth cations are removed throughout the acid treatment.

3. The ion exchange behavior of the Wyodak, Illinois \#6 coals and Beulah-zap coals are similar in the initial reactions with the acid. The amount of acid which reacts with the Wyodak or Beulah$\mathrm{Zap}$ is larger than that which reacts with the Illinois \#6 coal, indicating a greater capacity for the wyodak to exchange catalysts.

4. A small amount of inorganic material in the coal must be neutralized before the release of cations involved in ion exchange can be carried out.

5. Some aluminum is solubilized, possibly from the clays in the samples. clay is released following the acid treatment. This clay is possibly associated with the exchanged cations.

6. Clays present in the coal are probably involved in some of the ion exchange behavior and could provide a clay-supported catalyst in the coal sample in addition to the organically bound catalyst.

7. Catalysts can be added by both the ion exchange and adsorption technique. The reaction is slow indicating that adsorption may be the dominant mode of addition in these cases.

8. The initial oil yields indicate some reduction in going from raw to water-washed to acid-washed coal, which is thought to be due to the greater amount of handling or oxidation that may have occurred with the latter samples.

9. Illinois \#6 coal gave the best conversion with a variety of solvents for un-catalyzed samples.

have contributed to the conversions.

10. Black Thunder conversions were similar for addition of a single catalyst, and improved with two catalysts if one was either Mo or Fe. 
- FUTURE WORK:

Samples of Illinois \#6 coal have been acid washed and rinsed. These will be treated with Fe, or Co, or $\mathrm{Ni}$, or Mo. The treated samples as well as the acid washed without catalysts will then be sent for liquefaction evaluation.

A similar set of studies will be carried out with the Beulah-zap lignite for comparison and observation of trends with coal rank.

The Wyodak coal will be treated with a less oxidizing acid, such as sulfurous, to try to limit the potential oxidation of the sample.

The technique of catalyst addition will be refined to bettar understand the conditions which permit exchange of catalytic material with the coals. This work wiil be extended to addition of mixed catalysts, for example Fe or Co or Ni with Mo.

Samples will be dried before doing a titration curve to determine the sensitivity of the coal to pore structure collapse, and the effect of the collapse on the amount of catalyst which can be adsorbed.

\section{REFERENCES:}

1. K. S. Vorres, "Coal" in The Kirk-othmer Encylopedia of Chemical Technology, $\underline{6}, 423-489$ (1993).

2. K. Schroeder, Preprints, Am. Chem. Soc., Fuel Chem. Div. 38 (2) 512 (1993)

3. M. M. Taghiei, F. E. Huggins, B. Ganguly and G. P. Huffman, Preprints, Am. Chem. Soc., Fuel Chem. Div. 38 (1) 149 (1993)

4. K. S. Vorres, Annual Report to DOE/PETC "Ion Exchange and Adsorption on Low Rank Coals For Liquefaction", June, 1993, 33 pp.

5. P. R. Solomon, M. A. Serio, G. V. Deshpande and E. Kroo, Energy \& Fuels 4 42 (1990).

6. M. A. Serio, P. R. Solomon, G. V. Deshpande, E. Kroo, R. Bassilakis, D. McMillen, and R. Malhotra, Preprints, Fuel Chem. Div. Am. Chem. Soc., 35 (1) 61 (1990).

7. K. S. Vorres, Preprints, Am. Chem. Soc., Fuel Chem. Div. $\underline{38}$ (3) 1045 (1993).

8. K. S. Vorres, Energy Fuels, 4, 420-426 (1990).

9. D. J. Brockway and R. S. Higgins in The Science of Victorian Brown coal, ed. R. A. Durie, Butterworth-Heinemann, 1991, pp. 260 .

10. Y. Yun, B. L. Hoesterey, H. L. C. Meuzelaar and G. R. Hill, Preprints, Am. Chem. Soc., Fuel Chem. Div. 32 (4) 301 (1987). 
Figure 1.

Diagram of Equipment for Acid Leaching and Catalyst Application for Coal Samples

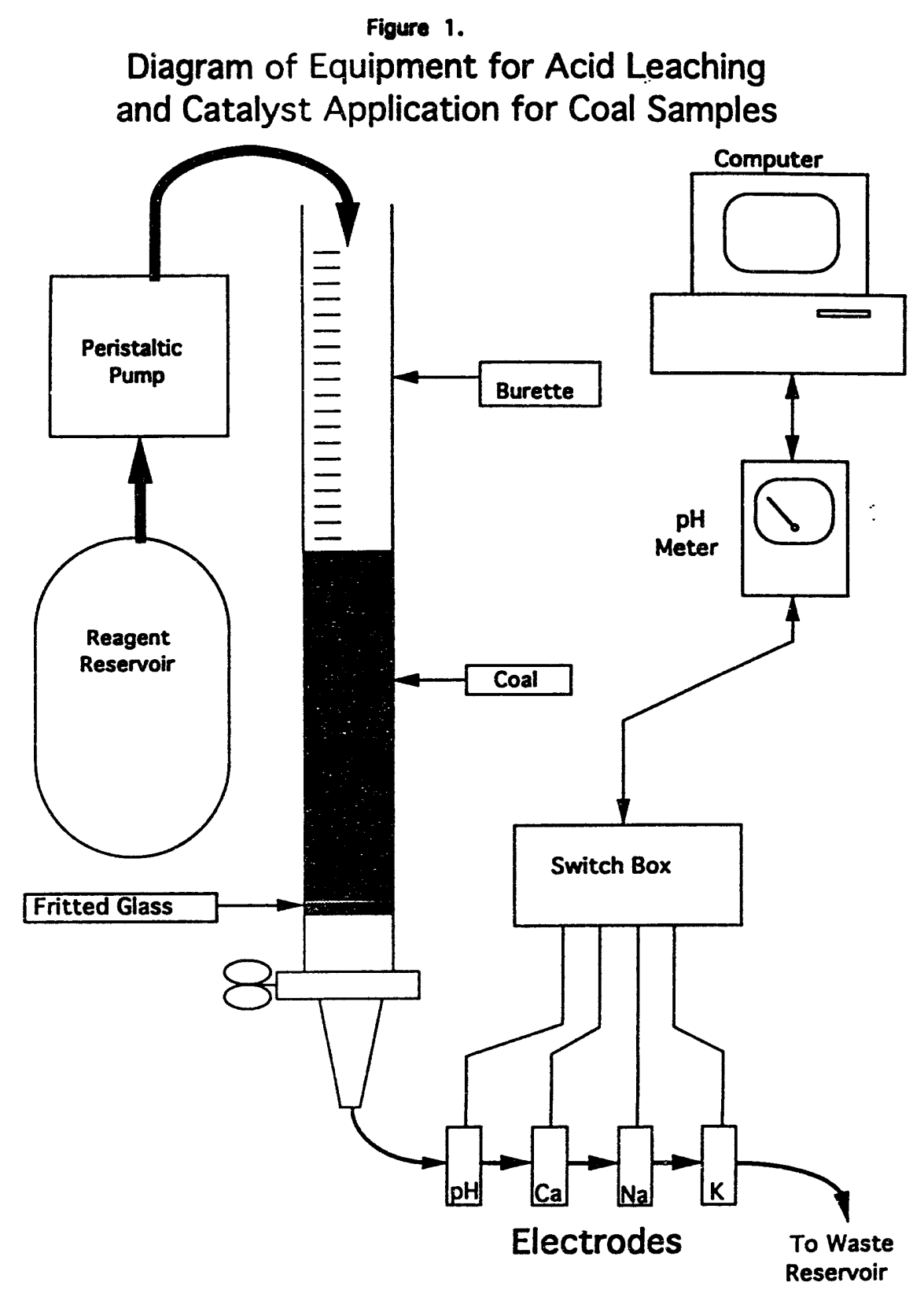

Fig. 2, Wyodak, First Acid Wash

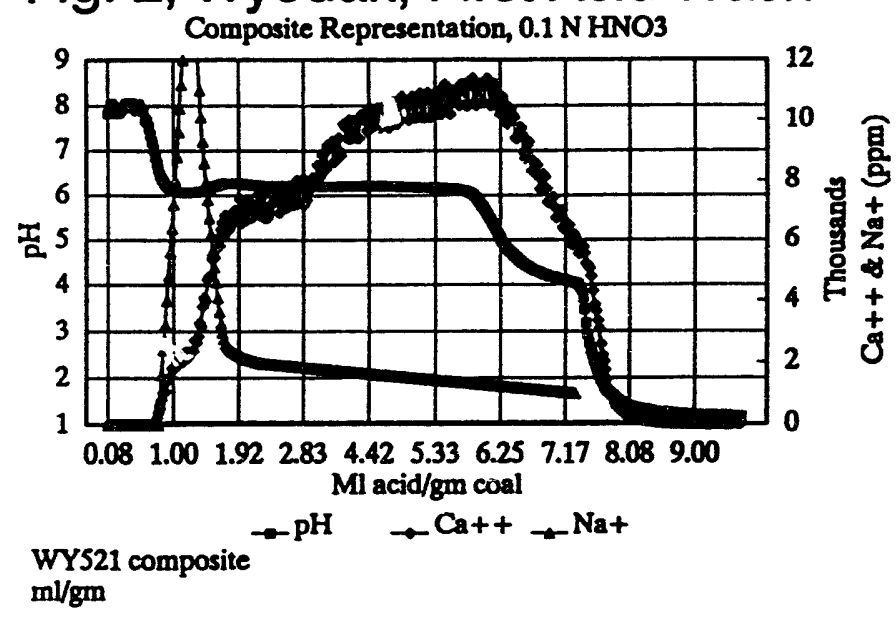

Fig. 3, 1st Water Rinse

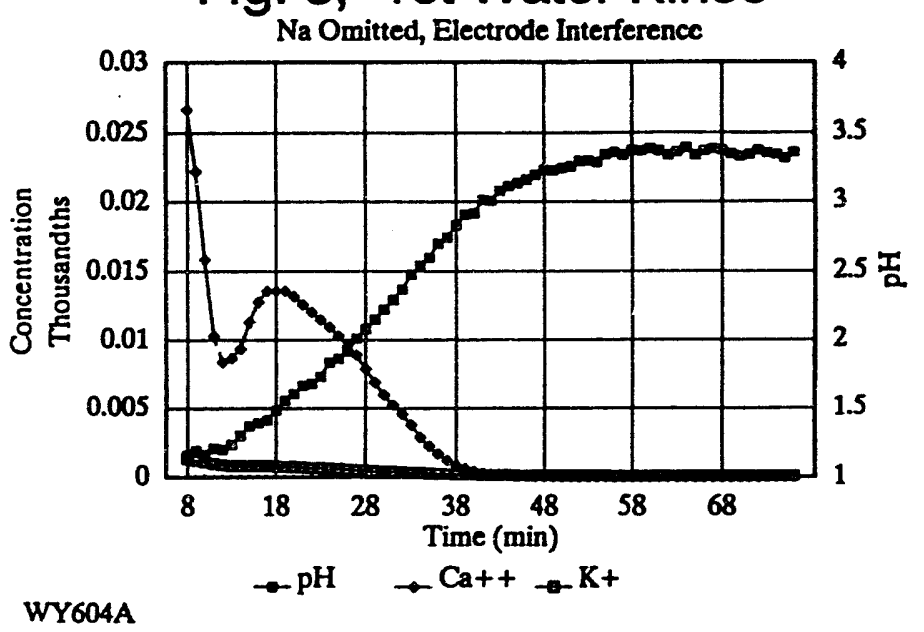


Fig. 4, Illinois \#6 Coal First Acid Wash 0.1 N HNO3

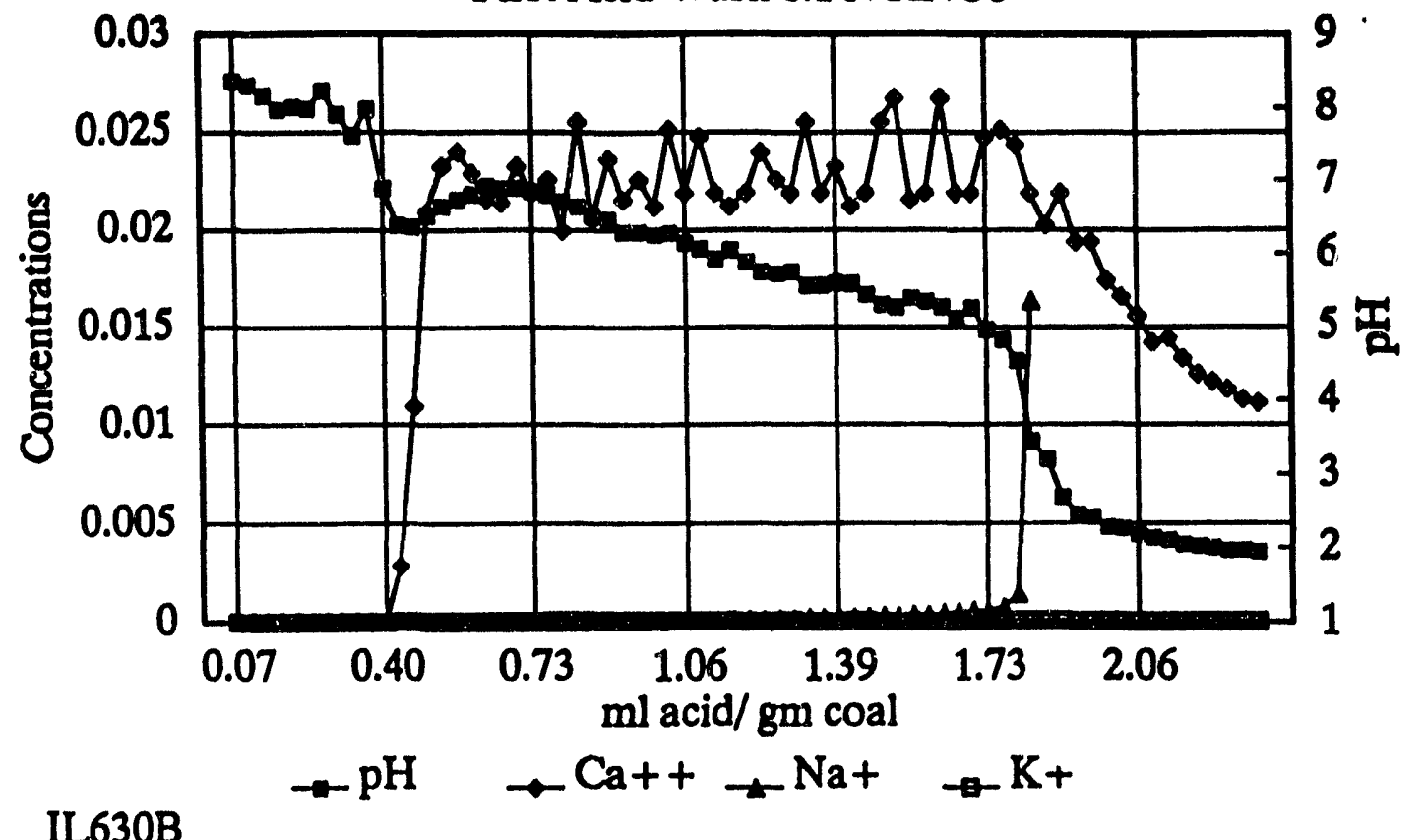

Fig4B

Fig. 5, Beulah-Zap Lignite

First Acid Titration, $0.1 \mathrm{~N} \mathrm{HNO} 3,30.52 \mathrm{~g}$ coal

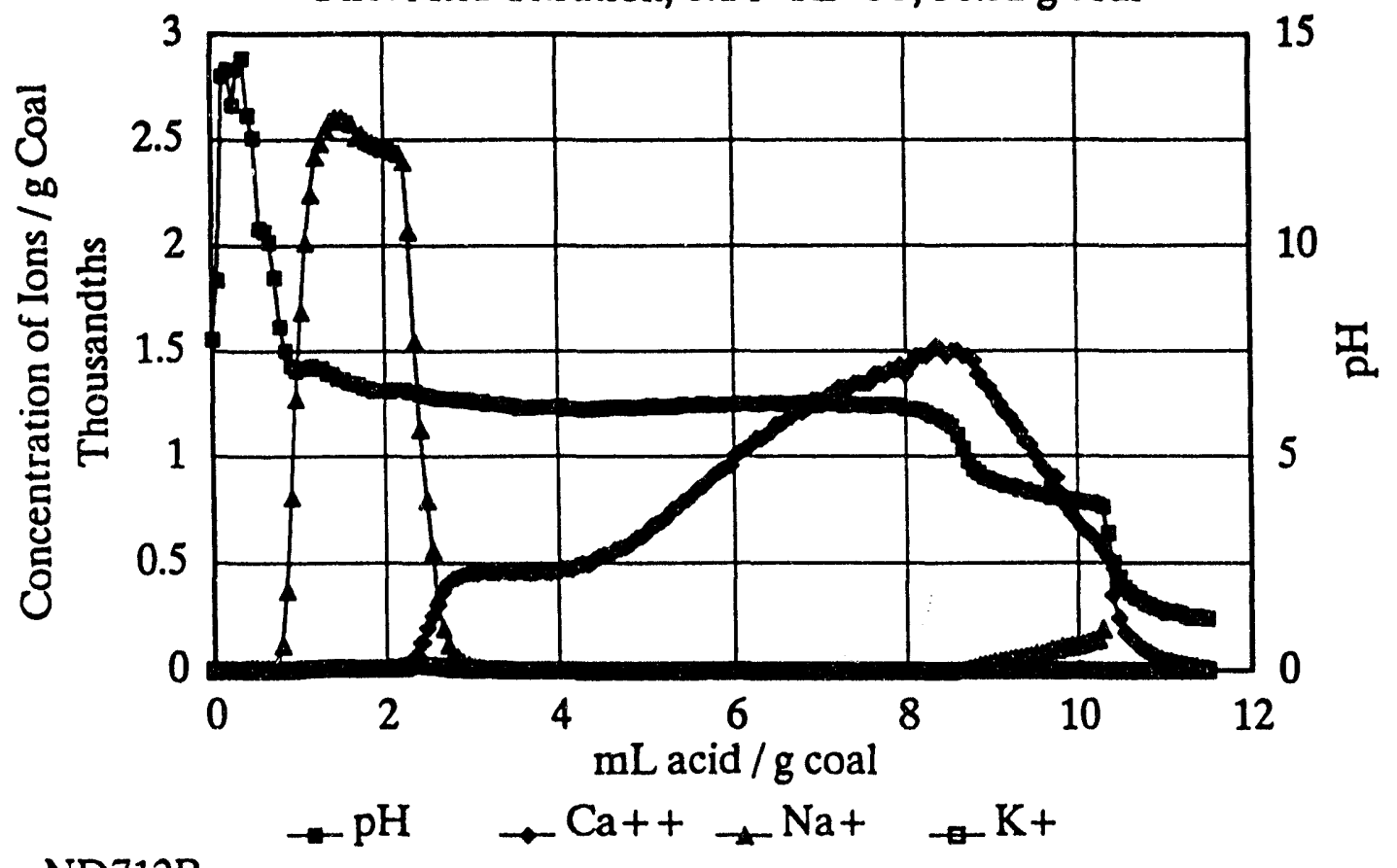

ND712B 

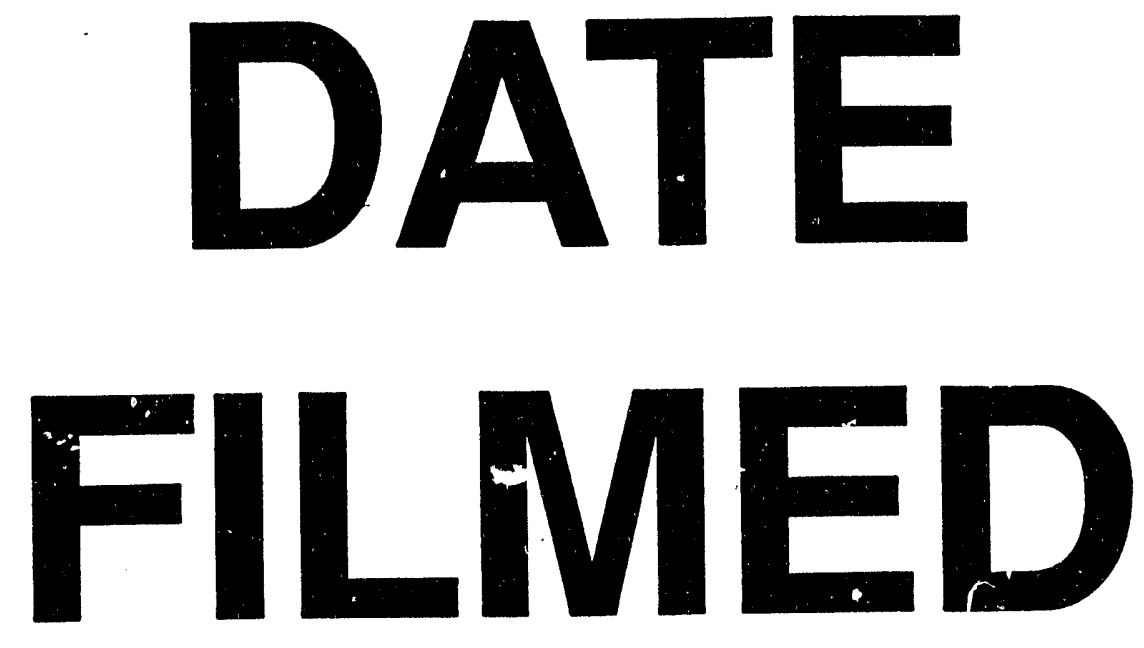

$10 / 18 / 94$
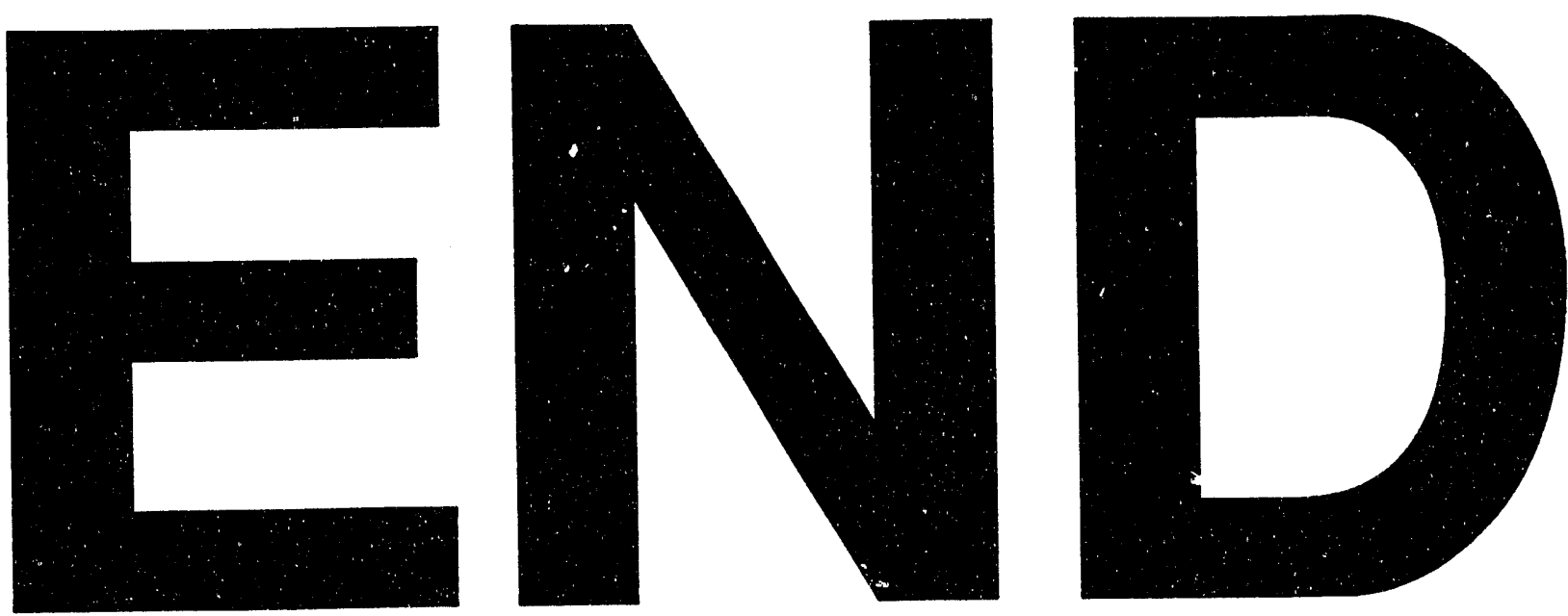
